\title{
Pyoderma gangrenosum in an abdominal surgical site: a case report
}

\author{
Kenichi Ogata, Hiroshi Takamori", Yoshiaki Ikuta, Hideyuki Tanaka, Nobuyuki Ozaki, Hiromitsu Hayashi, \\ Katsuhiro Ogawa and Koichi Doi
}

\begin{abstract}
Pyoderma gangrenosum (PG) is an uncommon, ulcerative skin disease that is often associated with systemic diseases. Herein, we report a development of PG in a surgical site after cholecystectomy that was difficult to discriminate from surgical site infection. The patient was a 74-year-old man who had previously been diagnosed with myelodysplastic syndrome (MDS). Laparoscopic cholecystectomy was planned under diagnosis of cholecystolithiasis, but we converted to open cholecystectomy. The surgical wound was partially erythematous 4 days after surgery. In spite of opening the wound, cleansing it with sterile saline, and administration of antibiotics, inflammation spread with erosion. The clinical manifestations and histopathologic features of biopsy specimen indicated that diagnosis of PG associated with MDS was most likely. Administration of glucocorticoids made a rapid response of skin inflammation. The differential diagnosis of postoperative wound healing complications that were unresponsive to conventional wound local care and antibiotic therapy should include PG, especially in patients with systemic diseases such as MDS.
\end{abstract}

Keywords: Pyoderma gangrenosum, Surgical site, Myelodysplastic syndrome

\section{Background}

Pyoderma gangrenosum (PG) is an uncommon, ulcerative skin disease, and characterized by a rapidly enlarging necrotic ulceration with an undermined border and a surrounding of erythema [1-5]. It is often associated with systemic illness, such as inflammatory bowel disease (IBD), rheumatoid arthritis (RA), and myelodysplastic syndrome (MDS) [6, 7]. Recently, several manuscripts reported that PG could also occur after surgery and local trauma [8-10]. Herein, we report a development of PG in a surgical site after cholecystectomy that was difficult to discriminate from surgical site infection.

\section{Case presentation}

The patient was a 74-year-old man who had previously been diagnosed with MDS. He was diagnosed with calculous cholecystolithiasis at our hospital. Laparoscopic cholecystectomy was planned, but we converted to open cholecystectomy with a right subcostal oblique incision because it was difficult to

* Correspondence: takamori60b@gmail.com

Department of Surgery, Saiseikai Kumamoto Hospital, 5-3-1 Chikami, Munami-ku, Kumamoto 861-4193, Japan remove the impacted calculus in the cystic duct. The surgical wound was partially erythematous 4 days after surgery (Fig. 1a), so we opened the wound and cleanse with sterile saline and performed moist environment dressing because of surgical site infection suspected. Inflammation, however, spread to the surrounding skin with erosion (Fig. 1b). The condition of wound rapidly deteriorated, so we introduced intrawound continuous negative pressure and irrigation treatment (IW-CONPIT) 10 days after surgery (Fig. 1c). In spite of IW-CONPIT, inflammation continued to further spread widely with a purulent coating (Fig. 1d). In addition, skin edema spread from the lower back to the lower extremities. Antibiotic administration and irrigation were not effective, either. Bacteriological examination revealed that Enterococcus faecalis and Pseudomonas aeruginosa were detected in the wound, although those counts were low. We decided to perform biopsy of the skin surrounding the wound to analyze pathological condition. Histopathologic feature showed that severe inflammatory cell, predominantly of neutrophils, infiltrated in the dermis, and no bacterial components were observed (Fig. 2a, b).
Springer

(c) 2015 Ogata et al. Open Access This article is distributed under the terms of the Creative Commons Attribution 4.0 International License (http://creativecommons.org/licenses/by/4.0/), which permits unrestricted use, distribution, and reproduction in any medium, provided you give appropriate credit to the original author(s) and the source, provide a link to the Creative Commons license, and indicate if changes were made. 

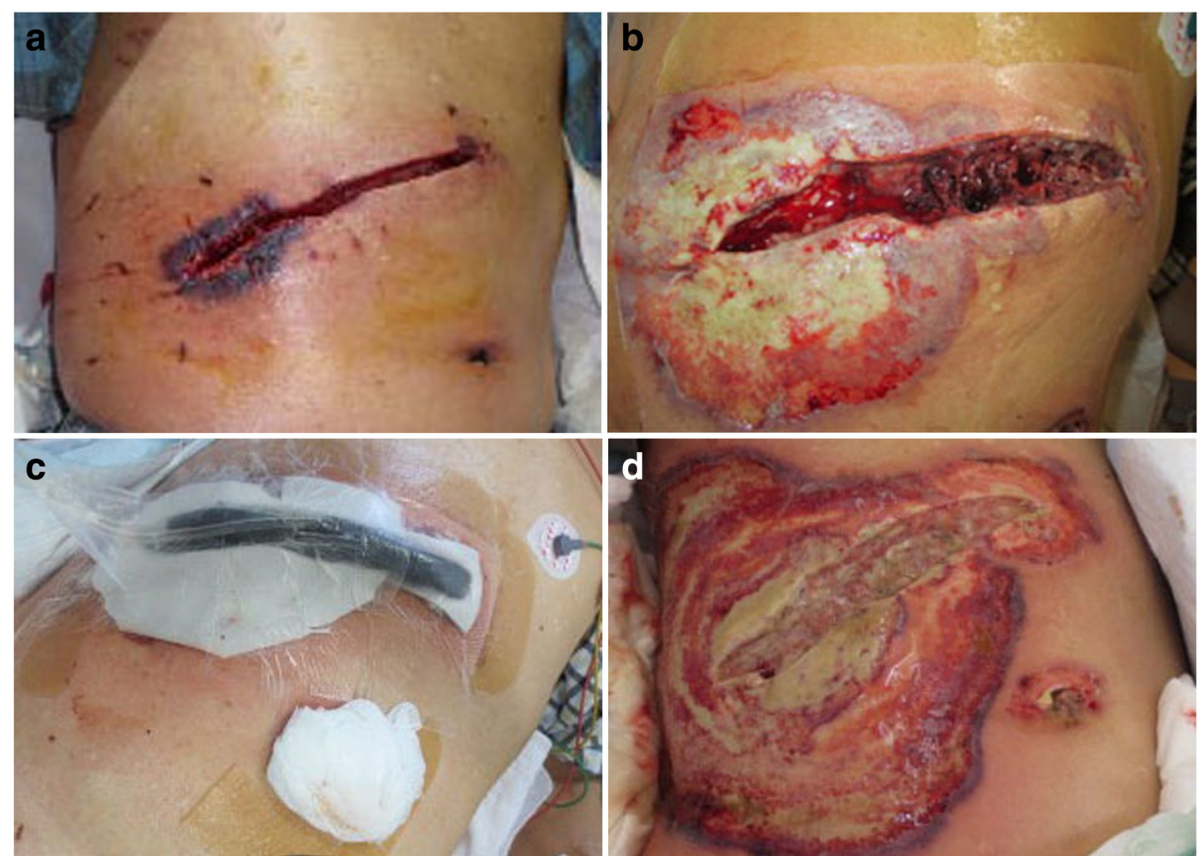

Fig. 1 Erythema occurred in the surgical site 4 days after surgery (a). The skin inflammation change spread with erosion despite that moist environment dressing was introduced (b). The intra-wound continuous negative pressure and irrigation treatment (IW-CONPIT) was also introduced from 10 days after surgery $(\mathbf{c})$. Inflammation continued to further spread with a purulent coating even after IW-CONPIT (d)

These clinical and histopathologic findings of the surgical site indicated that diagnosis of PG associated with MDS was most likely. After the addition of a systemic administration of $30 \mathrm{mg} /$ day prednisolone to local care of the surgical site with moist dressing, fever had been rapidly alleviated, spread of rash had diminished, edema in the lower body had improved, and the purulent coating had disappeared on the eroded skin surface surrounding the open wound (Fig. 3a). Elevated CRP (18.1 mg/dL) and WBC counts $\left(40.5 \times 10^{3} \mu \mathrm{L}\right)$ before administration of prednisolone had been improved remarkably, and these data became within normal ranges after
2 weeks, so the dose of prednisolone was tapered to $25 \mathrm{mg} /$ day. The dose had been reduced $5 \mathrm{mg} /$ day per 1-2 months to follow up the skin and general condition, including laboratory data. Erosion had healed and epithelialization occurred. The surface of the wound was covered with satisfactory granulation tissue, and normal wound healing was achieved after administration of $5 \mathrm{mg}$ /day prednisolone for 1 year (Fig. 3b).

\section{Discussion}

PG is an uncommon, chronic, recurrent, and painful cutaneous ulcerative disease with a distinctive

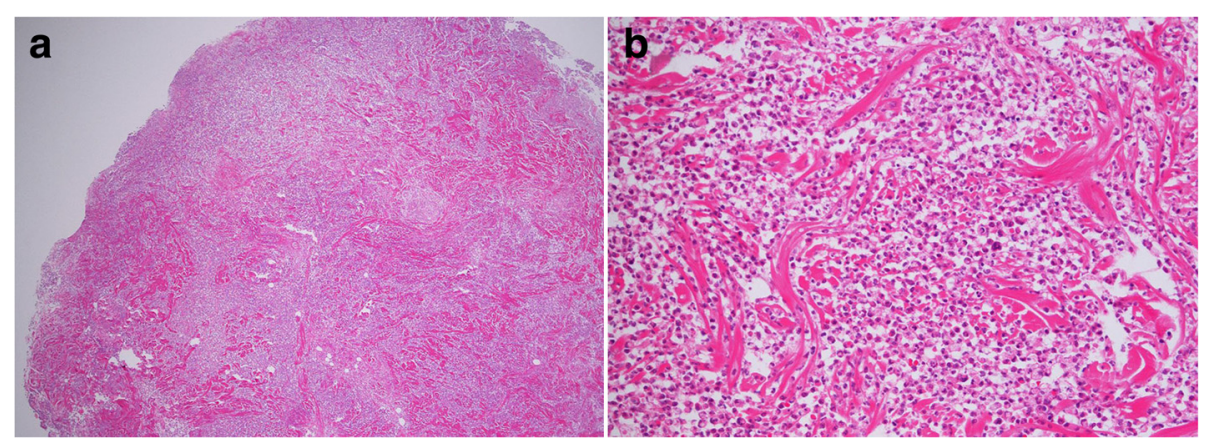

Fig. 2 Histological findings of the skin biopsy revealed that severe inflammatory cell, predominantly of neutrophils, infiltrated in the dermis, and no bacterial components were observed. Hematoxylin-eosin stain $\times 40(\mathbf{a}), \times 100(\mathbf{b})$ 


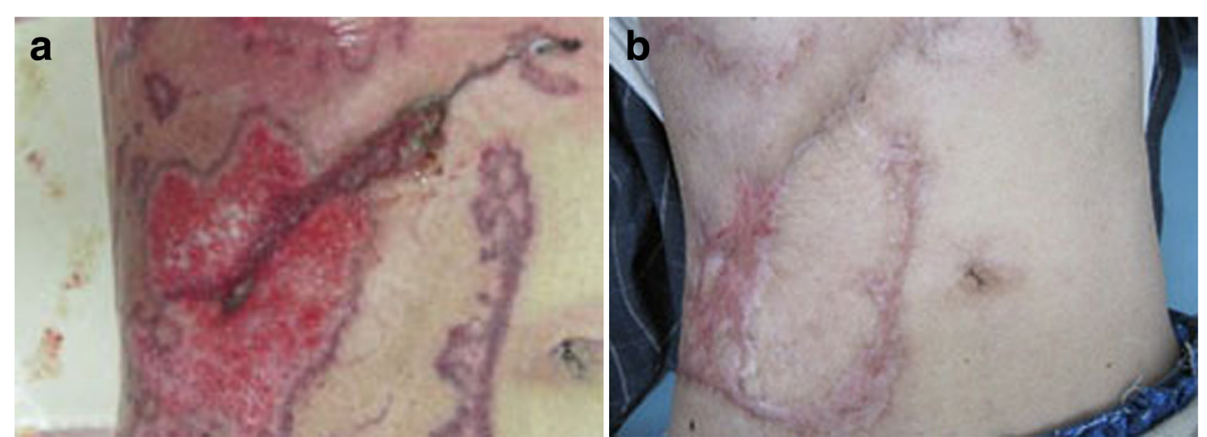

Fig. 3 After the systemic administration of glucocorticoid, the purulent coating had disappeared on the eroded skin surface in the surroundings of the open wound. In addition, erosion had healed and there was promotion of epithelialization (a). One year after surgery, normal wound healing was achieved (b)

morphologic presentation and uncertain etiology. The lower extremities are most common sites of involvement, though rare subtype of cases appears stoma site on ulcerative colitis increased recently [11]. More than half of patients with PG suffer from an associated systemic disease such as IBD, RA, and MDS [6,7]. In this case, there was a history of MDS: it was to help diagnosis of PG.

Development of PG in a surgical and trauma site is rare and occurs mainly within 2 weeks after surgery [12]. The initial symptoms are surgical site erythema and extreme pain out of proportion to the physical examination [13-17]. PG is often initially diagnosed as a surgical site infection, though treatment with antibiotics and wound debridement fails to arrest rapid ulcer enlargement. Our case was also regarded as infection to treat with antibiotics, open drainage, and continuous wound lavage, but the condition had been getting worse. We performed excisional biopsy to clarify pathogenesis of the cutaneous lesion. Histopathologic findings revealed non-specific and neutrophil-dominant inflammation, but bacterial infection could be denied. The clinical and histopathological manifestations indicated that diagnosis of PG associated with MDS was most likely. Histological examination should be performed to exclude other disorders such as vasculitis, pyoderma, and vasculopathies, when the administration of antibiotic, debridement, and irrigation for inflammatory surgical site is ineffective and makes clinical exacerbation. A diagnosis of PG could be made when other diagnostic possibilities had been excluded, because no accepted diagnostic criteria existed. $\mathrm{Su}$ WP et al. proposed diagnostic criteria, including clinical and histopathologic findings and treatment response [18]. Post-surgical PG occurred after breast (25\%), cardiothoracic (14\%), abdominal (14\%), and obstetric (13\%) surgeries [19], could deny infection and other possibilities, suspected PG, and performed experimental administration of steroid, following respond dramatically. PG has a good prognosis if appropriate therapy is immediately selected for it, but unless it is done, its prognosis becomes worse rapidly; it is likely to progress to death with consequent sepsis [20].

Definitive guidelines for treatment of PG are lacking. Patients with PG are treated with local and/or systemic therapies. First, to make an optimal environment for wound healing, a moist wound environment after cleansing with sterile saline is required [21]. Local administration of corticosteroids could be used in patients with mild PG, though the efficacy of these drugs is limited to a few retrospective studies and case reports [22, 23]. In contrast, systemic therapy is necessary in patients with more severe PG. Glucocorticoids are mostly selected for systemic drugs [22, 24]. Zuo et al. reported that most patients were treated with oral prednisolone $(0.5-1.5 \mathrm{mg} / \mathrm{kg} /$ day $)$ or intravenous methylprednisolone $(0.5-1 \mathrm{mg} / \mathrm{kg} /$ day $)$ combined with/without immunosuppressants such as systemic or topical tacrolimus [19]. We administered oral prednisolone $30 \mathrm{mg} /$ day $(0.5 \mathrm{mg} / \mathrm{kg} /$ day $)$ as initial treatment and by means of diagnostic administration. If this administration is not effective, the dose of oral prednisolone could increase or administrations of intravenous methylprednisolone and tacrolimus ointment could be selected. Topical tacrolimus is one of the effective local treatments for PG [25]. Cyclosporine exhibited equivalent effect compared with steroids as a systemic treatment in a randomized trial [26]. A wide variety of other systemic immunomodulatory drugs, including anti-tumor necrosis factor alpha agents could be also utilized as alternative or adjunctive treatments in patients with PG that fails to respond to glucocorticoids $[2,27]$.

\section{Conclusions}

The differential diagnosis of postoperative wound healing complications that were unresponsive to conventional wound debridement or antibiotic therapy should include PG, especially in patients with systemic diseases such as MDS. Glucocorticoids make a rapid response in patients with postoperative PG. 


\section{Consent}

Written informed consent was obtained from the patient for publication of this case report and any accompanying images. A copy of the written consent is available for review by the Editor-in-Chief of this journal.

\section{Abbreviations}

IBD: inflammatory bowel disease; IW-CONPIT: intra-wound continuous negative pressure and irrigation treatment; PG: pyoderma gangrenosum; MDS: myelodysplastic syndrome; RA: rheumatoid arthritis.

\section{Competing interests}

The authors declare that they have no competing interests.

\section{Authors' contributions}

$\mathrm{KO}$ and $\mathrm{HT}$ were the attending physicians of the case, conceived the design and analysis of the case, and drafted the manuscript. $\mathrm{YI}, \mathrm{HT}, \mathrm{NO}, \mathrm{HH}, \mathrm{KO}$, and $\mathrm{KD}$ participated in the design of this case presentation. All authors read and approved the final manuscript.

\section{Acknowledgements}

The authors thank Dr. Kamio for teaching histological findings.

Received: 7 September 2015 Accepted: 1 December 2015

Published online: 09 December 2015

\section{References}

1. Rozen SM, Nahadian MY, Manson PN. Management strategies for pyoderma gangrenosum: case studies and review of the literature. Ann Plat Surg. 2001; 47:310-5.

2. Brooklyn T, Dunnil D, Probert C. Diagnosis and treatment of pyoderma gangrenosum. BMJ. 2006:333:181-4.

3. Ruocco E, Sangiuliano S, Gravina AG, Miranda A, Nicoletti G. Pyoderma gangrenosum: an updated review. J Eur Acad Dermatol Venereol. 2009;23: 1008-17.

4. Nguyen $\mathrm{KH}$, Miller JJ, Helm K. Case reports and a review of the literature on ulcers mimicking pyoderma gangrenosum. Int J Dermatol. 2003;42:84-94.

5. Callen JP. Pyoderma gangrenosum. Lancet. 1998;351:581-5.

6. Wollona U. Pyoderma gangrenosum - a review. Orphanet J Rare Dis. 2007;2: 19-35.

7. Aractingi S, Bachmeyer C, Miclea JM, Verola O, Rousselot P, Dubertret L, et al. Unusual specific cutaneous lesions in myelodysplastic syndromes. J Am Acad Dermatol. 1995:33:187-91.

8. Sreenbrugge F, Raaijmaakers M, Caekebeke P, Van Landuyt K. Pyoderma gangrenosum following trauma of the knee: a case of pathergy and review of orthopaedic cases. Injury. 2011;42:421-3.

9. Ouazzani Al, Berhte JV, de Fontaine S. Post-surgical pyoderma gangrenosum: a clinical entity. Acta Chir Belg. 2007;107:424-8

10. Miron A, Giulea C, Tudose I, Petrache D, Giurcaneanu C. Pyoderma gangrenosum, rare parietal complication after colorectal surgery. Chirurgia. 2014;109:248-53.

11. Mancini GJ, Floyd I, Solla JA. Parastomal pyoderma gangrenosum: a case report and literature review. Am Surg. 2002;68:824-6.

12. Tolkachjov SN, Fahy AS, Wetter DA, Brough KR, Bridges AG, Davis MD, et al. Postoperative pyoderma gangrenosum (PG): the Mayo Clinic experience of 20 years from 1994 through 2014. J Am Acad Dermatol. 2015 doi:10.1016/j.jaad.2015.06.054

13. Lilford RJ, Tindall VR, Batchelar AG. Post-surgical pyoderma gangrenosum of the vaginal vault associated with ulcerative colitis: a case report. Eur J Obstet Gynecol Reprod Biol. 1989;31:93-4.

14. Pishori T, Quoreshi AH. Post-colectomy peristomal pyoderma gangrenosum. J Coll Surg Pak. 2005;15:121-2.

15. Long CC, Jessop J, Young M, Holt PJA. Minimising the risk of post-operative pyoderma gangrenosum. Br J Dermatol. 1992;127:45-8

16. Noblett SE, Woodcock S. Port-site pyoderma gangrenosum-a rare complication of surgical trauma. Ann R Coll Surg Engl. 2009;91:665-6.

17. Kotzampassakis N, Ksontini R. Pyoderma gangrenosum after inguinal hernia repair. Hernia. 2012;16:345-7.
18. Su WP, Davis MD, Weenig RH, Powell FC, Perry HO. Pyoderma gangrenosum: clinicopathologic correlation and proposed diagnostic criteria. Int J Dermatol. 2004;43:790-800.

19. Zuo KJ, Fung E, Tredget EE, Lin AN. A systematic review of post-surgical pyoderma gangrenosum: identification of risk factors and proposed management strategy. J Plast Reconstr Aesthet Surg. 2015;68:295-303.

20. Powell FC, Collins S. Pyoderma gangrenosum. Clin Dermatol. 2000;18:395.

21. Miller J, Yentzer BA, Clark A, Jorizzo JL, Feldman SR. Pyoderma gangrenosum: a review and update on new therapies. J Am Acad Dermatol. 2010;62:646-54

22. Reichrath J, Bens G, Bonowiz A, Tilgen W. Treatment recommendations for pyoderma gangrenosum: an evidence-based review of the literature based on more than 350 patients. J Am Acad Dematol. 2005:53:273-83.

23. Le Cleach L, Moguelet P, Perrin P, Chosidow O. Is topical monotherapy effective for localized pyoderma gangrenosum? Arch Dematol. 2011;147:101-3.

24. Binus AM, Qureshi AA, Li WW, Winterfield LS. Pyoderma gangrenosum: a retrospective review of patient characteristics, comorbidities and therapy in 103 patients. Br J Dermatol. 2011;165:1244-50.

25. Marzano AV, Trevisan V, Lazzari R, Crosti C. Topical tacrolimus for the treatment of localized, idiopathic newly diagnosed pyoderma gangrenosum. J Dermatolog Treat. 2010:21:140-3.

26. Ormerod AD, Thomas KS, Craig FE, Mitchel E, Greenlaw N, Norrie J, et al. Comparison of the two most commonly used treatments for pyoderma gangrenosum: results of the STOP GAP randomized controlled trial. BMJ. 2015;350:h2958

27. Saigal R, Singh Y, Mittal M, Kansal A, Maharia HR. Pyoderma gangrenosum. J Assoc Physicians India. 2010;58:378-83.

\section{Submit your manuscript to a SpringerOpen ${ }^{\circ}$ journal and benefit from:}

- Convenient online submission

- Rigorous peer review

- Immediate publication on acceptance

- Open access: articles freely available online

- High visibility within the field

- Retaining the copyright to your article

Submit your next manuscript at $\boldsymbol{s p r i n g e r o p e n . c o m ~}$ 